\title{
Occurrences of nitrosamines in chlorinated and chloraminated drinking water in three representative cities, China
}

\author{
Qian Luo, Donghong Wang, Zijian Wang * \\ State Key Laboratory of Environmental Aquatic Chemistry, Research Center for Eco-Environmental Science, Chinese Academy of Sciences, Beijing 100085, China
}

\section{H I G H L I G H T S}

- Nitrosamines in disinfected drinking water in three Chinese cities were investigated.

- Some nitrosamines could be detected in raw water.

- Advanced treatment affects nitrosamine levels both positively and negatively.

- Organic matters contribute to increased nitrosamine level.

- Nitrosamine levels in this study were below the EPA MAC but are still significant.

\section{A R T I C L E I N F O}

\section{Article history:}

Received 12 March 2012

Received in revised form 30 July 2012

Accepted 6 August 2012

Available online 30 August 2012

\section{Keywords:}

Nitrosamines

Disinfection by-products

Disinfecting drinking waters

Disinfection methods

UPLC-MS/MS

Health risk
G R A P H I C A L A B S T R A C T

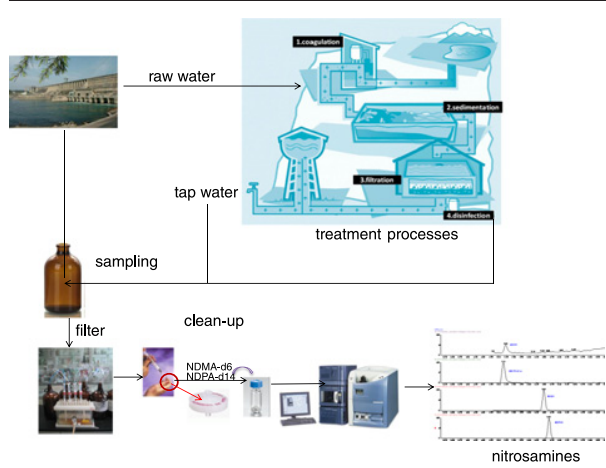

\section{A B S T R A C T}

An investigation of the occurrence of nine nitrosamines in drinking water following different water treatment processes was conducted using samples from seven drinking water treatment plants in three cities and tap waters in one city in China. The total nitrosamine levels ranged from not detected (n.d.) to $43.45 \mathrm{ng} / \mathrm{L}$. The species and concentrations of the nine nitrosamines varied with disinfection methods and source waters. $\mathrm{N}$-nitrosodimethylamine (NDMA), which is the nitrosamines of greatest concern, was identified in raw water, disinfecting water, finished water and tap water samples, ranging from 0.8 to $21.6,0.12$ to 24.2 , n.d. to 8.8, and n.d. to $13.3 \mathrm{ng} / \mathrm{L}$, respectively. Chloramination alone produced the most significant amounts of NDMA, while ozonation followed by chloramination led to moderately reduced levels. Additionally, chlorination produced relatively less NDMA, while low pressure ultraviolet radiation followed by chlorination could also significantly reduce them. Total organic carbon is one of the most important factors influencing nitrosamines formation in disinfecting water. In contrast, the addition of chlorine following any other disinfection was found to increase the formation of the other eight species of nitrosamines. The three nitrosamines recommended for monitoring by the US EPA were detected in the tap water samples, but most were present at levels below those that pose a risk to human health. Nevertheless, the occurrence and concentration of nitrosamines regulated in the Drinking Water Contaminant Candidate List could cause some potential human effects and therefore warrant attention.

(c) 2012 Elsevier B.V. All rights reserved.

\footnotetext{
* Corresponding author. Tel./fax: + 861062849140. E-mail address: wangzj@rcees.ac.cn (Z. Wang).
}

\section{Introduction}

Chlorine and chloramines are common chemical disinfectants that effectively harmful microorganisms in drinking water source waters such as rivers, lakes and groundwater. Disinfection by-products (DBPs) have been studied since the early 1970s, when trihalomethanes and 
haloacetic acids as DBPs were first detected in chlorinated drinking water. To date, more than 600-700 DBPs have been identified in drinking water (Krasner et al., 2006). Nitrosamines as emerging DBPs have become a concern of research recently, they have been shown to be present in meats, beers, pickles, tobacco smoke and may cause adverse effects on human health (IARC, 1978; Richardson, 2009). Nitrosodimethylamine (NDMA) was initially identified as a type of DBPs in drinking water in Ontario, Canada, in 1989 (Charrois et al., 2007), and as a groundwater contaminant at a northern California aerospace facility in 1998 (Najm and Trussell, 2001). In the last 10 years, the majority of studies of DBPs have focused on NDMA because it is most frequently detected in drinking water.

The United States Environmental Protection Agency (US EPA) has classified NDMA in Group B2 (probable carcinogenic effects on humans) under its 1986 carcinogen assessment guidelines (ATSDR, 1989). Furthermore, its toxicological effects are considered to be stronger than those of other nitrosamines, including nitrosomethylethylamine (NMEA), nitrosodiethylamine (NDEA), nitrosodi-npropylamine (NDPA), nitrosodi-n-butylamine (NDBA), nitrosodiphenylamine (NDPhA), nitrosopyrrolidine (NPyr), nitrosopiperidine (NPip) and nitrosomorpholine (NMor), which are suspected to be mutagenic compounds. The maximum admissible concentrations (MAC) of NDMA, NDEA and NMEA in water regulated by US EPA are 7,2 and $20 \mathrm{ng} / \mathrm{L}$, respectively, with cancer risk estimation of $1 \times 10^{-5}$ (IRIS, 2005). The California Department of Health Services (CDHS, 2007) has recommended that NDMA, NDEA and NDPA in drinking water have a notification level of $10 \mathrm{ng} / \mathrm{L}$. Hence, five nitrosamines (NDMA, NDEA, NDPA, NDPhA and NPyr) are now on the final version of the third Drinking Water Contaminant Candidate List (CCL-3) published by the US EPA in September of 2009 (US EPA, 2009).

NDMA was initially found in trace amounts and below the limit of detection in the source water in previous studies (Krasner et al., 2006; Charrois et al., 2007). However, significant amounts of NDMA were detected in both finished water from drinking water treatment plants (DWTPs) (up to $100 \mathrm{ng} / \mathrm{L}$ ) and distributed water (66 ng/L), which can be mainly attributed to the use of chlorine and chloramines for disinfection (Charrois et al., 2007). A nationwide survey of NDMA in raw water for DWTPs in Japan indicated that it was present at levels as high as $2.6 \mathrm{ng} / \mathrm{L}$ in the summer and $4.3 \mathrm{ng} / \mathrm{L}$ in the winter (Asami et al., 2009). Owing to the suspected human health risks of nitrosamines, considerable research has been conducted to monitor their occurrence in source water and their formation during drinking water treatment using different disinfection methods. Although the exact formation mechanisms of nitrosamines in source water are not certain, it is clear to some extent that disinfection processes can affect their formation (Richardson, 2009).

In China, source water and disinfection method used for drinking water vary greatly among cities and DWTPs. Additionally, there is concern that contaminated source water could be abstracted for drinking water due to water shortages. Generally speaking, there are high concentrations of organic matter in the source water, which affects water quality and public health and results in the regrowth of bacteria in distribution systems. Moreover, higher concentrations of DBPs may be produced during commonly used pre-chlorination processes. Nonetheless, the occurrence and distribution of nitrosamines are rarely examined in DWTPs and tap water in China, partly because they are not included in the drinking water quality standards. Moreover, determination of nitrosamines in drinking water is relatively difficult because they are present at concentrations of only a few ng/L. Furthermore, some compounds such as NDMA, NMEA and NDEA are characterized by an unfavorably low water/octanol partition coefficient, high polarity and solubility in water. Gas chromatography with mass spectrometry (GC/MS) with chemical ionization has commonly been used to detect nitrosamines in drinking water due to their low MAC for drinking water by the US EPA; however, this method cannot detect thermally labile compounds such as NDPhA and NMor (Munch and Bassett, 2004).
Therefore, liquid chromatography (LC) with tandem mass spectrometry (MS/MS) was initially applied to analyze NPip and NDPhA in water (Zhao et al., 2006). Recently, ultra performance liquid chromatography (UPLC) coupled with MS/MS was applied for the simultaneous analysis of all nine nitrosamines in water using solid-phase extraction (SPE) (Asami et al., 2009) and directly to detect these compounds without extraction or concentration procedures when they are present in relative high concentrations in drinking water (Luo et al., 2011).

In this study, an investigation of the occurrence of nitrosamines in DWTPs and typical tap water was conducted using SPE-UPLC-MS/MS. The species and concentrations of nine nitrosamines were simultaneously analyzed in raw water, finished water and the performance of unit processes (coagulation, filtration and/or biological activated carbon adsorption) in DWTPs adopting chlorine, chloriamine, and ultraviolet (UV) and ozone $\left(\mathrm{O}_{3}\right)$ as the disinfection methods. Possible factors influencing the production of and/or decreases in nitrosamines are also discussed based on investigation of large advanced water treatment plants in representative cities (Beijing, Shanghai, and Xuzhou) that employ typical disinfection methods in China.

\section{Materials and methods}

\subsection{Chemicals and reagents}

A standard solution ( $10 \mu \mathrm{g} / \mathrm{mL}$ each) containing the nine nitrosamines, NDMA, NMEA, NPyr, NPip, NMor, NDEA, NDPA, NDBA, and NDPhA, was purchased from Supelco (Oakville, ON, Canada). Isotopelabeled standards including $\left[6-\mathrm{H}^{2}\right] \mathrm{N}$-nitrosodimethylamine(NDMA$\mathrm{d}_{6}$ ) and $\left[14-\mathrm{H}^{2}\right] \mathrm{N}$-nitrosodi-n-propylamine (NDPA- $\mathrm{d}_{14}$ ) (98\%) were obtained from Cambridge Isotope Laboratories (Andover, MA). All other chemicals (n-hexane, acetonitrile, and methanol) were of analytical grade and obtained from Fisher Scientific (Nepean, ON, Canada) unless otherwise indicated. Ammonium acetate (ACS reagent grade) and acetate acid (analytical grade) were supplied by Sigma-Aldrich (Oakville, ON, Canada). Milli-Q water was used to dilute the mobile phase, solution and as blank samples (Millipore, Bedford, MA, USA). $0.45 \mu \mathrm{m}$ filter was obtained from Millipore and a $13 \mathrm{~mm} \times 0.2 \mu \mathrm{m}$ PSF GHP membrane filter needle was obtained from Pall Corporation (East Hills, USA).

A stock solution (1000 ng/L) containing the nine nitrosamines was prepared in methanol and stored at $4{ }^{\circ} \mathrm{C}$. Working solutions $(0.1-$ $1000 \mathrm{ng} / \mathrm{L}$ ) were prepared with 1:1 methanol/water purified using a Milli-Q system (Millipore, Bedford, MA, USA). Each working solution contained the surrogate standard NDMA- $\mathrm{d}_{6}(50 \mu \mathrm{g} / \mathrm{L})$ and the internal standard NDPA-d ${ }_{14}(50 \mu \mathrm{g} / \mathrm{L})$. All working solutions and ammonium acetate buffer were freshly prepared prior to UPLC-MS/MS analysis. The purity and stability of NDMA- $\mathrm{d}_{6}$ were determined by repeated analyses of NDMA-free water spiked with $40 \mathrm{ng} / \mathrm{L}$ of NDMA-d $\mathrm{d}_{6}$, and analyses conducted to confirm that the NDMA determined was found only in the samples.

\subsection{Safety}

$\mathrm{N}$-nitrosamines are potential carcinogens for humans and animals. Given the low volatility and skin permeability of NDMA, neither inhalation nor dermal exposure routes contribute significant amounts of exposure relative to the oral route. Safety precautions were taken when handling these compounds, and waste disposal was conducted according to proper safety procedures.

\subsection{Sampling and clean-up of water samples}

This representative survey of drinking water from different treatment processes (coagulation, filtration and/or biological activated carbon) in DWTPs was conducted from November 2009 (winter) to April 2010 (summer) in three cities in China. The sampling 
locations were selected because they were representative inland and coastal cities that employ different drinking water treatment technologies. Seven DWTPs were investigated, including four in city Beijing (B) that use three different surface water sources and one ground water source as the raw water, three other DWTPs of two cities Shanghai $(\mathrm{S})$ and Xuzhou $(\mathrm{X})$ use surface water as source water (A and B represent two treatment processes using same source waters). Samples of raw water, waters from treatment processes and finished water were collected from the DWTPs (drinking water treatment plant, abbr. $\mathrm{P}$ in this study). In addition, 30 tap water samples were collected from the water distribution system in city X. All water samples were immediately transported to our laboratory in glass containers under cool and dark conditions before preconcentration within one day against degradation (ATSDR, 1989). In addition, the total organic carbon (TOC), UV absorbance at $254 \mathrm{~nm}$ (UVA 254), pH value, turbidity and color analyses were performed according to the standard methods (APHA, 1998).

Nitrosamines are characterized by an extremely low water/ octanol partition coefficient. The retention of nitrosamines in the sorbents of LiChrolut EN and Oasis HLB is mainly owing to hydrophobic interactions, and the recoveries range from 95 to 103\% (Jurado-Sanchez et al., 2010). In this study, the extraction of nitrosamines from water samples was performed using HLB and Sep-Pak ® Plus AC-2 Cartridge SPE. Briefly, each packed SPE cartridge was initially rinsed with $15 \mathrm{~mL}$ each of dichloromethane and methanol, after which the residual organic solvents were removed under vacuum. The combined SPE cartridges were then conditioned with $15 \mathrm{~mL}$ each of methanol and water. NDMA-d $\mathrm{d}_{6}$ was spiked into the sample (final concentration of $50 \mu \mathrm{g} / \mathrm{L}$ ). The sample passed through the SPE cartridge at a flow rate of $3-5 \mathrm{~mL} / \mathrm{min}$. The analytes absorbed onto the SPE cartridges were then eluted using $15 \mathrm{~mL}$ of dichloromethane. The organic eluents were collected and concentrated to $400 \mu \mathrm{L}$ under high purity nitrogen. The internal standard NDPA- $\mathrm{d}_{14}$ (final concentration of $50 \mu \mathrm{g} / \mathrm{L}$ ) was added to the extract prior to the UPLC-MS/MS analysis.

\subsection{UPLC-MS/MS analysis}

The analytical protocols used for the analysis of nine nitrosamines in drinking water were based on the procedure described by Luo et al. (2011). Briefly, UPLC analyses were performed using a Waters Acquity Ultra Performance LC system (Waters, Milford, MA, USA). UPLC separation was achieved using an Acquity UPLC ${ }^{\text {TM }}$ HSS T3 column $(50 \mathrm{~mm} \times 2.1 \mathrm{~mm}$, i.d., $1.8 \mu \mathrm{m}$ particle size, Waters, Milford MA, US), maintained at $40^{\circ} \mathrm{C}$, with a mobile phase flow rate of $0.2 \mathrm{~mL} / \mathrm{min}$. The sample volume injected was $10 \mu \mathrm{L}$. The mobile phase was composed of solvent A $(5 \mathrm{mmol} / \mathrm{L}$ or $10 \mathrm{mmol} / \mathrm{L}$ ammonium acetate in water, $\mathrm{pH}=3.5-4.0)$ and solvent $\mathrm{B}(100 \%$ acetonitrile). The solvent gradient program consisted of $40 \%$ solvent B for $0.5 \mathrm{~min}$, increasing solvent B from $40 \%$ to $90 \%$ over $5 \mathrm{~min}$, continuously increasing solvent B to $100 \%$, and then returning solvent B back to $50 \%$ over $0.5 \mathrm{~min}$, followed by a $0.5 \mathrm{~min}$ re-equilibration prior to the next sample injection.

Analysis was performed using a Waters Micromass Quattro Premier XE tandem quadrupole mass spectrometer (Waters, Manchester, UK). In this study, characteristic ions of the parent compounds and product ions for nine nitrosamines using the electrospray ionization (ESI), whereas the atmospheric pressure chemical ionization could not generate the parent ion of NDPhA that is thermally unstable (Luo et al., 2011). Positive ESI combined with the multiple reaction monitoring (MRM) mode was applied in this study. The ionization source parameters were as follows: capillary voltage $2.8 \mathrm{kV}$; source temperature $120^{\circ} \mathrm{C}$; desolvation gas temperature $380{ }^{\circ} \mathrm{C}$ applied at a flow rate of $600 \mathrm{~L} / \mathrm{h}\left(\mathrm{N}_{2}\right)$; cone gas flow rate $50 \mathrm{~L} / \mathrm{h}$. Nitrogen (99.9\% purity) and argon (99.9999\% purity) were used as the cone and collision gases, respectively. MRM transitions and the individual cone voltage and collision energy voltages applied for the analysis are summarized in Appendix A (Table S1). The dwell time established for each transition was $50 \mathrm{~ms}$, and the inter-scan delay was set at $10 \mathrm{~ms}$. Data acquisition was carried out using the MassLynx V 4.1 software.

Standard solutions of $5-200 \mu \mathrm{g} / \mathrm{L}$ with $\mathrm{NDPA}-\mathrm{d}_{14}$ as internal standard $(50 \mu \mathrm{g} / \mathrm{L})$ and NDMA- $\mathrm{d}_{6}$ (surrogate standard, $50 \mu \mathrm{g} / \mathrm{L}$ ) were analyzed using UPLC-MS/MS according to the optimized chromatographic separation and MS detection conditions. MRM chromatograms of the nine nitrosamines in the water samples are shown in Fig. S1.

\subsection{Quality assurance and quality control}

The relative response factors (RRFs) of the nine target nitrosamines and the surrogate standard (NDMA- $\mathrm{d}_{6}$ ) were calculated based on the ratio of the relative peak area of the individual analytes to that of the internal standard (NDPA- $\mathrm{d}_{14}$ ) automatically obtained by the TargetLynx software. The reproducibility of RRFs was also determined. Quality control measures included the injection of a blank solution consisting of the mobile phase to check for carryover after each sample and a set of standard solutions of $1-500 \mu \mathrm{g} / \mathrm{L}$ to calculate the RRF of each compound before and after a set of authentic drinking water samples. The linear relationship, limit of detection (LOD) and limit of quantitation (LOQ) are shown in Table S1. Determination of the nine nitrosamines in six Milli-Q water samples spiked with standards solutions $10 \mathrm{ng} / \mathrm{L}$, the average values of the nine nitrosamines are $0.7-0.9 \mathrm{ng} / \mathrm{L}$ (the recovery of SPE is $70-90 \%$ ).

\section{Results and discussion}

\subsection{Possible occurrence and human risks of nitrosamines}

Nine species of nitrosamines present in various levels in raw water, the treatment process (filtration, active carbon adsorption/ sedimentation), and finished water from seven DWTPs in three representative cities ( $\mathrm{B}, \mathrm{S}$ and $\mathrm{X}$ ) in China and tap water in one city $(\mathrm{X})$ were investigated. The concentrations of the nine nitrosamines are summarized in Tables 1 and 2. NDMA was obviously the most frequently detected nitrosamine and was present in the highest concentrations in the seven DWTPs. It is important to note that NDMA was found in relatively high levels in raw water from several sampling locations, ranging from 3.95 to $21.6 \mathrm{ng} / \mathrm{L}$ in city B, 0.12 to $12.88 \mathrm{ng} / \mathrm{L}$ in city S and n.d. to $0.8 \mathrm{ng} / \mathrm{L}$ in city X. Raw water in P1, P2 and P3 came from three different surface water reservoirs (inland rivers), while that in $\mathrm{P} 4$ was from ground water that was subjected to very simple prechlorination disinfection. This is the first time that NDMA was detected in untreated water in China, indicating that this compound is present in the aquatic environment. These findings are consistent with the results of previous studies in which NDMA was found at $4.3 \mathrm{ng} / \mathrm{L}$ in raw waters from Japan (Asami et al., 2009) and up to $53.5 \mathrm{ng} / \mathrm{L}$ in raw waters from five untreated source waters in Canada and United States (Zhao et al., 2008). The NDMA level was $3.95 \mathrm{ng} / \mathrm{L}$ in the influent water sample from P4 (untreated ground water). It is not clear why NDMA was detected in surface and ground waters in China. NDMA in liquid rocket fuels was the source of contamination of groundwater at rocket testing facilities in Sacramento County, CA, that had concentrations of up to $40 \mu \mathrm{g} / \mathrm{L}$ onsite and up to $20 \mu \mathrm{g} / \mathrm{L}$ offsite (Mitch et al., 2003). Further research indicated that this may have been due to chlorinated wastewater being used for groundwater recharge. In addition, some of the NDMA might be derived from the interaction of chlorination chemicals with dimethylamine (DMA) functional groups on polymers used for water filtration (Mitch and Sedlak, 2004).

NDMA concentrations in finished waters in this study ranged from 0.7 to $8.8 \mathrm{ng} / \mathrm{L}$, with most samples containing concentrations lower 
Table 1

Species and concentration ng/L of nine nitrosamines in DWTPs in three cities in China.

\begin{tabular}{|c|c|c|c|c|c|c|c|c|c|c|c|}
\hline & DWTPs & Treatment process & NDMA & NMor & NPyr & NMEA & NDEA & NPip & NDPA & NDBA & NDPhA \\
\hline \multirow[t]{21}{*}{ B } & \multirow[t]{4}{*}{ P1-1A } & Raw water & 11.95 & n.d. & 1.25 & n.d. & 9.40 & n.d. & n.d. & n.d. & n.d. \\
\hline & & Filtration & 13.40 & n.d. & n.d. & n.d. & 6.40 & 4.50 & n.d. & 3.50 & n.d. \\
\hline & & AC adsorption & 12.35 & 12.20 & 2.75 & n.d. & 5.80 & n.d. & n.d. & 1.55 & n.d. \\
\hline & & Finished water & 8.80 & n.d. & n.d. & n.d. & n.d. & n.d. & n.d. & n.d. & n.d. \\
\hline & \multirow[t]{4}{*}{ P1-1B } & Raw water & 15.25 & 8.10 & 1.23 & n.d. & 9.60 & n.d. & n.d. & n.d. & n.d. \\
\hline & & Filtration & 19.30 & n.d. & n.d. & n.d. & 9.30 & n.d. & n.d. & 0.90 & 0.55 \\
\hline & & AC adsorption & 15.5 & n.d. & 6.55 & n.d. & 6.10 & n.d. & n.d. & 0.10 & n.d. \\
\hline & & Finished water & 5.50 & n.d. & n.d. & n.d. & n.d. & n.d. & n.d. & n.d. & n.d. \\
\hline & \multirow[t]{4}{*}{ P2 } & Raw water & 13.5 & 17.05 & n.d. & n.d. & n.d. & 4.00 & n.d. & 0.80 & n.d \\
\hline & & Filtration & 9.20 & 10.90 & n.d. & n.d. & n.d. & 6.85 & n.d. & n.d. & 0.15 \\
\hline & & AC adsorption & 6.20 & 11.80 & n.d. & n.d. & n.d. & 6.25 & n.d. & n.d. & 0.55 \\
\hline & & Finished water & 3.45 & 14.55 & n.d. & n.d. & n.d. & 2.90 & n.d. & n.d. & 0.30 \\
\hline & \multirow[t]{3}{*}{ P3-3A } & Acceleration pond & 21.6 & 7.80 & n.d. & n.d. & 8.15 & n.d. & n.d. & 0.90 & 0.50 \\
\hline & & Filtration & 20.75 & 7.75 & n.d. & 14.95 & n.d. & n.d. & n.d. & n.d. & n.d. \\
\hline & & AC adsorbed & 11.95 & n.d. & n.d. & 20.05 & n.d. & 2.70 & n.d. & 2.10 & n.d. \\
\hline & \multirow[t]{4}{*}{ P3-3B } & Acceleration pond & 12.30 & 5.20 & n.d. & n.d & n.d. & n.d. & n.d. & 0.10 & 0.15 \\
\hline & & Filtration & 23.80 & n.d. & 6.35 & n.d. & 8.15 & 2.90 & n.d. & 1.40 & n.d. \\
\hline & & AC adsorption & 24.20 & n.d. & 2.10 & n.d. & 10.85 & n.d. & n.d. & n.d. & n.d. \\
\hline & & Finished water & 0.70 & n.d. & 3.75 & n.d. & n.d. & n.d. & n.d. & n.d. & n.d. \\
\hline & \multirow[t]{2}{*}{ P4 } & Influent & 3.95 & 4.40 & n.d. & n.d. & n.d. & n.d. & n.d. & n.d. & n.d. \\
\hline & & Effluent & 4.50 & 14.8 & 10.60 & 8.05 & n.d. & n.d. & n.d. & 0.20 & 0.05 \\
\hline \multirow[t]{6}{*}{ S } & \multirow[t]{3}{*}{ P5 } & Raw water & 12.90 & 6.47 & 2.93 & n.d. & 6.55 & n.d. & n.d. & 0.90 & n.d. \\
\hline & & Sedimentation & 18.90 & 3.65 & 2.68 & n.d. & 7.87 & n.d. & n.d. & 0.43 & n.d. \\
\hline & & Finished water & 3.53 & 5.28 & 1.60 & n.d. & n.d. & n.d. & n.d. & n.d. & 0.05 \\
\hline & \multirow[t]{3}{*}{ P6 } & Raw water & 0.50 & n.d. & n.d. & 1.22 & n.d. & n.d. & 0.88 & n.d. & 0.02 \\
\hline & & Pre-chlorination/coagulation & 0.12 & n.d. & 0.18 & 0.60 & 0.17 & 0.06 & n.d. & n.d. & 0.01 \\
\hline & & Finished water & n.d. & n.d. & 0.04 & 1.00 & n.d. & 0.04 & n.d. & n.d & n.d. \\
\hline \multirow[t]{4}{*}{$\mathrm{X}$} & \multirow[t]{4}{*}{ P7 } & Raw water & 0.80 & n.d. & 0.13 & n.d. & n.d. & 0 & n.d. & 0.02 & n.d. \\
\hline & & Filtration & 0.70 & 3.50 & n.d. & n.d. & n.d. & n.d. & n.d. & n.d. & n.d. \\
\hline & & Sedimentation & n.d. & 0.30 & n.d. & n.d. & 0.10 & 0.09 & 0.54 & n.d. & n.d. \\
\hline & & Finished water & n.d. & n.d. & n.d. & n.d. & n.d. & n.d. & n.d. & n.d. & n.d. \\
\hline
\end{tabular}

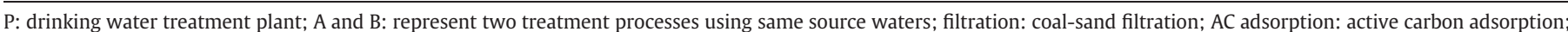
n.d.: not detected.

than the MAC for water set by the US EPA ( $7 \mathrm{ng} / \mathrm{L}$ ), except for one sample $(\mathrm{P} 1-1 \mathrm{~A})$ that contained $8.8 \mathrm{ng} / \mathrm{L}$. These concentrations are lower than the notification level (10 ng/L) (CDHS, 2007); indicating

Table 2

Occurrence of nine nitrosamines $\mathrm{ng} / \mathrm{L}$ in tap water from a distribution system in city X.

\begin{tabular}{|c|c|c|c|c|c|c|c|c|c|}
\hline Location & NDMA & Nmor & Npyr & NMEA & NDEA & Npip & NDPA & NDBA & NDPhA \\
\hline 1 & 1.2 & 2.3 & n.d. & n.d. & n.d. & 0.1 & n.d. & n.d. & n.d. \\
\hline 2 & 5.8 & 5.1 & n.d. & 1.4 & n.d. & n.d. & n.d. & 3.1 & n.d. \\
\hline 3 & 4.3 & 4.4 & 8.6 & 2.8 & n.d. & n.d. & 10.1 & 0.9 & 0.1 \\
\hline 4 & 10.8 & n.d. & n.d. & n.d. & n.d. & n.d. & 5.9 & n.d. & 0.5 \\
\hline 5 & 6.1 & 4.1 & n.d. & n.d. & 6.8 & 0.6 & n.d. & 0.3 & n.d. \\
\hline 6 & 2.6 & n.d. & n.d. & n.d. & n.d. & n.d. & n.d. & 1.4 & n.d. \\
\hline 7 & 6.6 & n.d. & n.d. & 1.1 & n.d. & n.d. & 11.1 & n.d. & n.d. \\
\hline 8 & n.d. & n.d. & n.d. & 2.6 & n.d. & 1.3 & n.d. & n.d. & n.d. \\
\hline 9 & 7.1 & n.d. & n.d. & 5.8 & n.d. & n.d & n.d. & n.d. & n.d. \\
\hline 10 & 13.3 & 4.7 & n.d. & n.d. & n.d. & n.d. & n.d. & n.d. & n.d. \\
\hline 11 & 8.7 & 3.9 & n.d. & n.d. & n.d. & n.d. & n.d. & 0.8 & n.d. \\
\hline 12 & 1.2 & 3.6 & n.d. & n.d. & n.d. & n.d. & n.d. & n.d. & n.d. \\
\hline 13 & n.d. & 2.4 & n.d. & n.d. & n.d. & n.d. & n.d. & n.d. & n.d. \\
\hline 14 & 1.9 & 2.0 & n.d. & n.d. & n.d. & 0.1 & n.d. & n.d. & n.d. \\
\hline 15 & n.d. & 2.1 & n.d. & 0.3 & n.d. & 0.1 & n.d. & n.d. & n.d. \\
\hline 16 & n.d. & n.d. & n.d. & n.d & 9.7 & n.d. & n.d. & n.d. & n.d. \\
\hline 17 & n.d. & n.d. & n.d. & n.d & 7.1 & n.d. & n.d. & n.d. & n.d. \\
\hline 18 & n.d. & 1.9 & n.d. & 1.7 & n.d & n.d. & n.d. & n.d. & n.d. \\
\hline 19 & n.d. & n.d. & n.d. & n.d. & 7.4 & n.d. & 10.9 & n.d. & n.d. \\
\hline 20 & n.d. & n.d. & n.d. & n.d. & n.d. & n.d. & n.d. & n.d. & n.d. \\
\hline 21 & n.d. & n.d. & n.d. & n.d. & n.d. & n.d. & n.d. & n.d. & n.d. \\
\hline 22 & n.d. & 2.4 & n.d. & n.d. & 7.7 & n.d. & n.d. & n.d. & n.d. \\
\hline 23 & n.d. & n.d. & n.d. & n.d. & n.d. & n.d. & n.d. & n.d. & n.d. \\
\hline 24 & n.d. & n.d. & 0.9 & n.d. & 7.1 & n.d. & n.d. & 0.6 & n.d. \\
\hline 25 & n.d. & n.d. & n.d. & n.d. & n.d. & n.d. & n.d. & n.d. & n.d. \\
\hline 26 & n.d. & 6.1 & n.d. & n.d. & 8.8 & n.d. & n.d. & n.d. & n.d. \\
\hline 27 & n.d. & 2.3 & n.d. & n.d. & n.d. & n.d. & n.d. & 1.2 & n.d. \\
\hline 28 & n.d. & n.d. & n.d. & n.d. & n.d. & n.d. & n.d. & n.d. & n.d. \\
\hline 29 & n.d. & 2.9 & n.d. & n.d. & n.d. & n.d. & n.d. & n.d. & n.d. \\
\hline 30 & n.d. & n.d. & n.d. & n.d. & n.d. & n.d. & n.d. & n.d. & n.d. \\
\hline
\end{tabular}

that the presence of NDMA in finished water in the three cities in China investigated in the present study should not pose a severe human health risk. The concentration of NDMA reached $0.6-1.0 \mathrm{ng} / \mathrm{L}$ in only one raw water sample, but was as high as $30 \mathrm{ng} / \mathrm{L}$ in 81 finished water samples collected from 21 North American DWTPs (Barrett et al., 2003). Overall, the NDMA levels in three representative cities in China (n.d. to $24.2 \mathrm{ng} / \mathrm{L}$ ) were within the range observed (n.d. to $118.1 \mathrm{ng} / \mathrm{L}$ ) in disinfection treatment process water samples in Canada and the United States (Zhao et al., 2008).

NDMA was found in 30 tap water samples at levels ranging from n.d. to $13.3 \mathrm{ng} / \mathrm{L}$, although it was not identified in finished water collected from DWTPs in city X. These findings are very similar to those observed when NDMA was investigated in distribution system water collected from 21 North American DWTPs (Barrett et al., 2003). However, an investigation of 20 municipal drinking water distribution systems in Alberta, Canada and 179 DWTPs in Ontario revealed NDMA concentrations of up to $100 \mathrm{ng} / \mathrm{L}$ and $66 \mathrm{ng} / \mathrm{L}$, respectively (Charrois et al., 2007). As shown in Fig. 1, the species and concentrations of nitrosamines in municipal drinking water distribution systems were related to the distance from DWTPs and the water distribution pipe network. Our results are different from those of previous studies, in that they suggest that the concentrations of nitrosamines increase with increasing distance from treatment plants (CDHS, 2007). In fact, at a sampling point (location 4 , shown in Table 2 ) some distance from the treatment plant the concentration of NDMA was nearly 200 times greater than the recommended maximum for drinking water in the region. This is probably related to the presence of residual disinfectant in the water distribution system, coupled with the availability of nitrogenous compounds as precursors to form NDMA.

In addition to NDMA, four other nitrosamines included in the CCL3 set by the US EPA (NDEA, NDPA, NDPhA and NPyr) were found at various levels in the collected water samples. NDEA was detected in raw water and treatment process water samples at levels ranging 


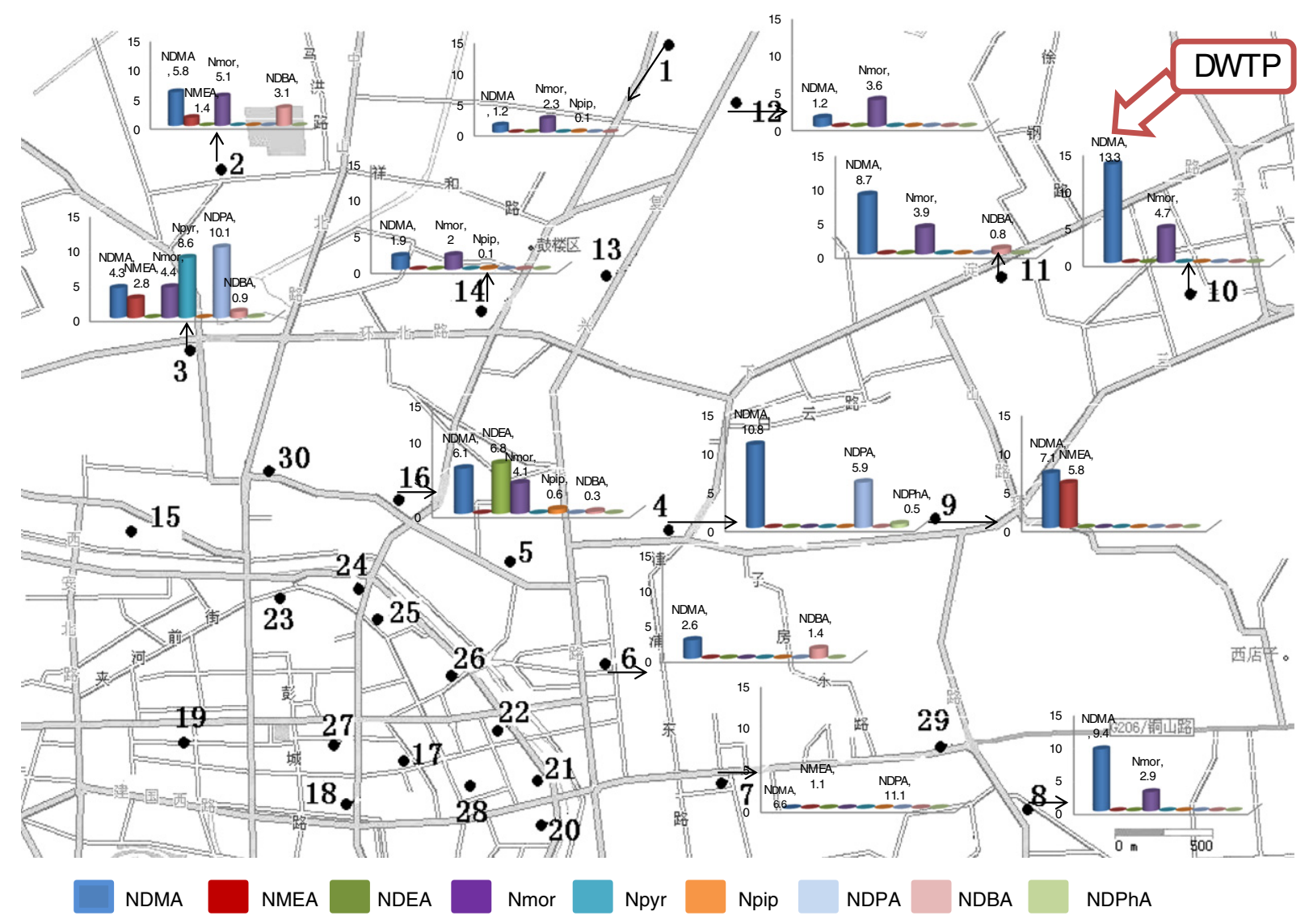

Fig. 1. Occurrence of nitrosamine in distribution supplies at various sampling locations in city X (concentration units: ng/L).

from n.d. to $10.85 \mathrm{ng} / \mathrm{L}$, but was not found in the finished water of four DWTPs in city B. NDEA was found in raw water and settled water in $\mathrm{P} 5$ at $6.55 \mathrm{ng} / \mathrm{L}$ and $7.87 \mathrm{ng} / \mathrm{L}$, and in raw water and coagulated water in P6 at n.d. and $0.17 \mathrm{ng} / \mathrm{L}$, respectively, but was not found in finished water in city S. NDEA was not found in raw water or water from the treatment processes, but was detected in finished water at $10 \mathrm{ng} / \mathrm{L}$ and in eight tap water samples collected in city X at levels ranging from 6.8 to $9.7 \mathrm{ng} / \mathrm{L}$. Overall, the concentrations of NDEA and NDPA were not much higher than the notification level of $10 \mathrm{ng} / \mathrm{L}$ set by the CDHS (2007).

NDPA was only detected in raw water of P6 and in sedimentation of P7 at 0.88 and $0.54 \mathrm{ng} / \mathrm{L}$, respectively. NDPhA was found in raw water from P6, accelerated water in P3-3A and P3-3B, treatment process and finished water in P2, and finished water in P4, P5 and P6, at levels ranging from 0.01 to $0.3 \mathrm{ng} / \mathrm{L}$. The NPip concentrations ranged from 2.9 to $6.85 \mathrm{ng} / \mathrm{L}$ in treatment process samples collected from four plants in city B. In addition, NPip was detected at trace concentrations (n.d. to $0.13 \mathrm{ng} / \mathrm{L}$ ) in source water samples from three of nine locations, and at $0.04 \mathrm{ng} / \mathrm{L}$ and $0.13 \mathrm{ng} / \mathrm{L}$ in finished water from P6 and P5, respectively. NDPhA, NPyr and NPip were not found in DWTPs in city X; however, NPip was found in four of 26 tap water samples at levels ranging from 0.1 to $1.3 \mathrm{ng} / \mathrm{L}$. Especially, NDPhA was found in tap water samples from two sampling locations at low concentrations ( 0.1 and $0.5 \mathrm{ng} / \mathrm{L}$ in locations 3 and 4 ) (Fig. 1). NMEA was not detected in all samples from city B, but was found in raw water, water that had been treated with chlorine, and finished water in P6 in city S at levels ranging from 0.59 to $1.22 \mathrm{ng} / \mathrm{L}$. NDBA was found in raw water $(0.90 \mathrm{ng} / \mathrm{L})$ and treatment process samples $(0.43 \mathrm{ng} / \mathrm{L})$; however, it was not found in finished water samples from P5. NMEA was not found in treatment plants, but was found in tap water sample levels ranging from 1.1 to $5.8 \mathrm{ng} / \mathrm{L}$ of four locations in city X.

\subsection{Factors influencing the formation of nitrosamines}

Four disinfection treatments were used in the seven DWTPs investigated in this study, chlorine $\left(\mathrm{OCl}^{-}\right)$, chloramines $\left(\mathrm{NH}_{2} \mathrm{Cl}\right)$, ozone followed by chloramines $\left(\mathrm{NH}_{2} \mathrm{Cl} / \mathrm{O}_{3}\right)$, and low pressure UV followed by chlorine $\left(\mathrm{OCl}^{-} / \mathrm{LPUV}\right)$. Chloramination in practice does not involve adding preformed chloramines but normally involves adding ammonia and chlorine, usually with the chlorine first. $\mathrm{OCl}^{-}$is the most popular disinfection method in China and is used at P2, P3 and P7. $\mathrm{NH}_{2} \mathrm{Cl}$ was only used at P1. The disinfection methods used in city $\mathrm{S}$ differ slightly from those used in $\mathrm{B}$ and $\mathrm{X}$ in that $\mathrm{P} 5$ consists of $\mathrm{OCl}^{-}$/LPUV and $\mathrm{P} 6$ uses $\mathrm{NH}_{2} \mathrm{Cl} / \mathrm{O}_{3}$.

Our results showed that the concentrations of NDMA and the other eight nitrosamines varied with the four disinfection methods. Several studies have recently demonstrated the effects of different disinfection treatments on nitrosamine formation. For example, chloramination alone or chlorination of water containing ammonia has been shown to produce significant amounts of NDMA (Choi et al., 2002; Schreiber and Mitch, 2006). Additionally, source waters from two locations were found to produce similar amounts of NDMA after treatment with either $\mathrm{OCl}^{-}$or $\mathrm{NH}_{2} \mathrm{Cl}$, and the highest concentration of NDMA was produced with $\mathrm{NH}_{2} \mathrm{Cl}$ disinfection of source water (Zhao et al., 2008).

Unexpectedly results that NDMA was not only produced in the disinfection processing as DBPs that was also detected in raw water with differing concentrations. The concentrations of NDMA in raw water from P1 were similar to those from P2, P3 and P5, but NDMA 
concentrations in finished water from P1 were higher than the others. These results are consistent with those of previous reports that chloramination may produce more NDMA than chlorination, and that NDMA concentrations in waters disinfected by chlorination are typically less than $10 \mathrm{ng} / \mathrm{L}$ for surface waters (Najm and Trussell, 2001). NDMA levels in finished water of $P 6$ decreased to n.d. after $\mathrm{O}_{3}$ treatment. Published kinetic data also suggested that $\mathrm{O}_{3}$ treatment reduced NDMA formation by oxidizing any secondary amines present in the source water (Zhao et al., 2008); however, this is based on the assumption that $\mathrm{O}_{3}$ treatment removes DMA by completely mineralizing the secondary amine (Andrzejewski et al., 2008). Several alternative disinfectants such as $\mathrm{O}_{3}$ are able to produce nitrosamines, but usually at lower concentrations than chloramines (Najm and Trussell, 2001; Andrzejewski et al., 2008). In contrast, UV and advanced oxidation processes have both been investigated as possible strategies to decrease or eliminate nitrosamine in water (Stefan and Bolton, 2002; Lee et al., 2005; Landsman et al., 2007). In fact, NDMA levels of $\mathrm{P} 5$ decreased to $3.5 \mathrm{ng} / \mathrm{L}$ in finished water after $\mathrm{LPUV} / \mathrm{OCl}^{-}$treatment.

As mentioned above, NMor was detected in raw, filtered, AC adsorbed and finished water samples of P2, P4 and P5, while NMEA was present in filtered and AC adsorbed water of P3 and P6, NDPhA was found in filtered, AC adsorbed and finished water of P2 and P6 (P2, $\mathrm{P} 3$ and $\mathrm{P} 4$ were treated using $\mathrm{OCl}^{-}, \mathrm{P} 5$ using $\mathrm{OCl}^{-} / \mathrm{LPUV}$ and $\mathrm{P} 6$ using $\mathrm{NH}_{2} \mathrm{Cl} / \mathrm{O}_{3}$ ). These results are in accordance with those of previous studies in which NMor was detected in $\mathrm{O}_{3} / \mathrm{OCl}^{-}$disinfected water, $\mathrm{NDPhA}$ in $\mathrm{OCl}^{-}$and $\mathrm{NH}_{2} \mathrm{Cl}$ treated samples, and NMEA in $\mathrm{OCl}^{-}$ and medium-pressure UV/OCl ${ }^{-}$disinfected water (Zhao et al., 2008). The highest concentrations of NMor, NMEA, and NDPhA observed in this study were $14.8,1.22$ and $0.55 \mathrm{ng} / \mathrm{L}$, which are similar to the results of previous studies in which the highest levels of those compounds were $19.1,0.55$, and $0.23 \mathrm{ng} / \mathrm{L}$, respectively (Zhao et al., 2008).

Two emerging nitrosamines in drinking water distribution systems, NDPhA and NPip, were not present in the raw water (P3 and P6) or were present at levels lower than those in the finished water (P2); hence, they could have been generated during the disinfection process. NPyr and NMor were first found in drinking water distribution systems from in a city in Canada that employed chloramines in combination with UV disinfection, at concentrations of $2-4 \mathrm{ng} / \mathrm{L}$ and $1 \mathrm{ng} / \mathrm{L}$, respectively (Charrois et al., 2004). It is important to note that NPyr and NMor have not previously been found in source water and finished water. Similarly, they were not found in water treated only by chloramination disinfection in this study. This may reflect the difference in precursors available in the source water and their reactivity with $\mathrm{O}_{3}$ and $\mathrm{OCl}^{-}$. In a previous study, NDPhA (0.2-0.6 ng/L) was formed after disinfection with $\mathrm{OCl}^{-}$, $\mathrm{NH}_{2} \mathrm{Cl}, \mathrm{O}_{3}$ and $\mathrm{MPUV} / \mathrm{OCl}^{-}$. NMEA was produced with $\mathrm{OCl}^{-}$and $\left(\mathrm{MPUV} / \mathrm{OCl}^{-}\right.$), while NMor formation was associated with $\mathrm{O}_{3}$ (Zhao et al., 2008).

The formation of NDMA as a result of chlorine treatment could have occurred via reaction with nitrogen precursor, natural ammonia in the source water or nitrogen-containing coagulants used in the water-treatment process (Mitch et al., 2003; Wilczak et al., 2003). Some studies revealed that chlorination of water containing DMA, methylethylamine, diethylamine and diphenylamine in the presence of ammonia ions results in the formation of NDMA, NMEA, NDEA and NDPhA, respectively (Choi et al., 2002; Andrzejewski et al., 2005; Zhou et al., 2009). These findings indicate that most nitrosamines are usually formed by nitrosation or oxidation of amine precursors in the process of disinfection. In fact, these specific precursors may have been present in the source waters in this study; however, more investigations are needed to identify their presence.

In general, DBP formation is a complicated process that is influenced by many variables including $\mathrm{pH}$, temperature, turbidity, natural organic matter (NOM) content and concentration in source water, as well as the type and concentration of the disinfectants used and disinfectant contact time. A recent study by Hua and Reckhow (2007) reported that the formation of unknown total organic halogens is greater during chloramine treatment than chlorine treatment. Enhanced coagulation, active carbon (AC) and preozonation were found to improve NOM removal. The organic matter in source water may include NOM and anthropogenic pollutants, especially in areas of China such as Yangtze River Delta, and metropolitan areas including Shanghai. The TOC of raw water of P1 from surface water reservoirs ranges from 3.1 to $4.0 \mu \mathrm{g} / \mathrm{mL}$, and of P2 from 0.1 to $0.5 \mu \mathrm{g} / \mathrm{mL}$. The species and concentrations of nine nitrosamines in P1 (1A and 1B) water, which was disinfected by chloramines, was not significantly different from that of P2, P3 and $\mathrm{P} 4$, which was treated by chlorine. The all 31 sampling locations of the seven DWTPs had TOC values that ranged from 0.83 to $3.3 \mathrm{mg} / \mathrm{L}$ and UV 254 readings that ranged from 0.001 to $0.182 \mathrm{~cm}^{-1}$ (Table S2). The highest values of TOC and SUV254 are related to the number of nitrosamine species in source waters using different disinfection treatments (Zhao et al., 2008). The raw water in P5, which had a higher TOC (2.5 ppm), was from a reservoir close to the Yangtze River Estuarine that is influenced by saline water invasion and eutrophication. However, NDMA is at a low concentration level $(0.12 \mathrm{ng} / \mathrm{L})$ in raw water from P6 with a low TOC value $(0.14 \mathrm{ppm})$. The source water of P6 is from Huangpu River, which has a relatively high TOC (2.1-2.5 ppm). In general, the NDMA concentration decreased as the TOC decreased in raw, filtered, AC adsorbed and finished water in this study.

\section{Conclusions}

This study investigated the species and concentrations of nine nitrosamines found in drinking water samples collected from DWTPs in three typical cities using representative disinfection methods in China. NDMA was the most frequently detected nitrosamine in all water samples. The results support previous observations that chloramination alone or chlorination of water containing ammonia produced significant amounts of NDMA, and those subsequent advanced processes such as $\mathrm{O}_{3}$ and UV removal of nitrosamines were effective for raw water with low turbidity and high TOC. The results also confirmed that subsequent chlorination following alternative treatment can slightly increase the NDMA concentration and lead to the formation of other nitrosamines such as NDEA, NMEA, NPip and NDPA in river water from Inland River. The formation of different nitrosamines in raw water suggests that NOM and/or anthropogenic contaminants may contain different subunits for the formation of various nitrosamines; therefore, the determination of precursors of various nitrosamines in source water will be further investigated. Nine nitrosamines were found in tap water samples, most of which were present at levels less than the MAC for water regulated by the US EPA, accordingly, which should not lead to potential health risks. However, investigation of whether the occurrence and concentration of regulated and un-regulated nitrosamines have the potential to cause human effects should be conducted.

\section{Acknowledgments}

This study was partially supported by grants from the National Natural Science Foundation of China (NSFC21007077), Sino-US cooperation project of the Ministry of Science and Technology of China (2009DFA91920), Environmental Protection National Commonweal Research Project (200909040), and the Ministry of Water Resources' special funds for scientific research on public causes (201201032).

\section{Appendix A. Supplementary data}

Supplementary data to this article can be found online at http:// dx.doi.org/10.1016/j.scitotenv.2012.08.023. 


\section{References}

Agency for Toxic Substances, Disease Registry (ATSDR). Toxicological profile for N-nitrosodimethylamine. Prepared by the Syracuse Research Corporation for ATSDR in collaboration with the U.S. Environmental Protection Agency. Washington, D.C.: U.S. Public Health Service; 1989. 119 pp.

American Public Health Association (APHA). Standard methods for the examination of water and wastewater. 20th edition. Washington, D.C.: American Public Health Association; 1998

Andrzejewski P, Kasprzyk-Hordern B, Nawrocki J. The hazard of N-nitrosodimethylamine (NDMA) formation during water disinfection with strong oxidants. Desalination 2005;176:37-45.

Andrzejewski P, Kasprzyk-Hordern B, Nawrocki J. N-nitrosodimethylamine (NDMA) formation during ozonation of dimethylamine-containing waters. Water Res 2008;42(4-5):863-70.

Asami M, Oya M, Kosaka K. A nationwide survey of NDMA in raw and drinking water in Japan. Sci Total Environ 2009;40(11):3540-5.

Barrett S, Hwang C, Guo YC, Andrews SA, Valentine R. Occurrence of NDMA in drinking water: North American survey, 2001-2003. Proceedings of American WaterWorks Association annual conference and exhibition, Anaheim, CA; 2003.. June, CD ROM.

California Department of Health Services (CDHS). Public health goal for $\mathrm{N}$-Nitrosodimethylamine in drinking water. URL:http://www.oehha.ca.gov/ water/phg/pdf/122206NDMAphg.pdf. 2007. (accessed February, 2012).

Charrois JWA, Arend MW, Froese KL, Hrudey SE. Detecting N-nitrosamines in drinking water at nanogram per liter levels using ammonia positive chemical ionization. Environ Sci Technol 2004;38:4835-41.

Charrois JWA, Boyd JM, Froese KL, Hrudey SE. Occurrence of N-nitrosamines in Alberta public drinking-water distribution systems. J Environ Eng Sci 2007;6:103-14.

Choi J, Duirk SE, Valentine RL. Mechanistic studies of N-nitrosodimethylamine (NDMA) formation in chlorinated drinking water. J Environ Monit 2002;4:249-52.

Hua GH, Reckhow DA. Comparison of disinfection byproduct formation from chlorine and alternative disinfectants. Water Res 2007;41:1667-78.

Integrated Risk Information System (IRIS). United States Environmental Protection Agency (EPA), Office of Research and Development (ORD), National Center for Environmental Assessment. http://www.epa.gov/iris/ 2005. (accessed March, 2012).

International Agency for Research on Cancer (IARC). N-Nitrosodimethylamine. In Some N-nitroso compounds. IARC Monogr Eval Carcinog Risks Hum 1978;17:125-75.

Jurado-Sanchez B, Ballesteros E, Gallego M. Evaluation of stationary phases and gas chromatographic detectors for determination of amines in water. J Sep Sci 2010;33:3365-73.

Krasner SW, Weinberg HS, Richardson SD, Pastor SJ, Chinn R, Sclimenti MJ, et al. Occurrence of a new generation of disinfection byproducts. Environ Sci Technol 2006;40:7175-85.
Landsman NA, Swancutt KL, Bradford CN, Cox CR, Kiddle JJ, Mezyk SP. Free radical chemistry of advanced oxidation process removal of nitrosamines in water. Environ Sci Technol 2007;41:5818-23.

Lee C, Choi W, Yoon J. UV photolytic mechanism of N-nitrosodimethylamine in water: roles of dissolved oxygen and solution pH. Environ Sci Technol 2005;39:9702-9.

Luo Q, Wang DH, Wang BY, Zhang ZQ, Wang Z. Rapid and sensitive method for simultaneous determination of nine $\mathrm{N}$-nitrosamines in drinking water by UPLC-MS/MS. Sci China B 2011;41:82-90.

Mitch WA, Sedlak DL. Characterization and fate of N-nitrosodimethylamine precursors in municipal wastewater treatment plants. Environ Sci Technol 2004;38:1445-54.

Mitch WA, Sharp JO, Trussell RR, Valentine RL, Alvarez-Cohen L, Sedlak DL. $\mathrm{N}$-nitrosodimethylamine (NDMA) as a drinking water contaminant: a review. Environ Eng Sci 2003;20:389-404.

Munch JW, Bassett MV. Determination of nitrosamines in drinking water by solid phase extraction and capillary column gas chromatography with large volume injection and chemical ionization tandem mass spectrometry (MS/MS). EPA/600/R-05/054. http://www.epa.gov/microbes/m_521.pdf. 2004.

Najm I, Trussell RR. NDMA formation in water and wastewater. J Am Water Works Assoc 2001;93:92-9.

Richardson SD. Water analysis: emerging contaminants and current issues. Anal Chem 2009;81:8654. 8654.

Schreiber IM, Mitch WA. Nitrosamine formation pathway revisited: the importance of chloramine speciation and dissolved oxygen. Environ Sci Technol 2006;40: 6007-14.

Stefan MI, Bolton JR. UV direct photolysis of N-nitrosodimethylamine (NDMA): kinetic and product study. Helv Chim Acta 2002;85:1416-26.

United States Environmental Protection Agency (US EPA). Final contaminant candidate list 3 microbes: identifying the universe. http://water.epa.gov/scitech/drinkingwater/dws/ccl/ccl3.cfm. 2009. (accessed March, 2012).

Wilczak A, Assadi-Rad A, Lai HH, Hoover LL, Smith JF, Berger R, et al. Formation of NDMA in chloraminated water coagulated with DADMAC cationic polymer. J Am Water Works Assoc 2003;95:94-106.

Zhao YY, Boyd J, Hrudey SE, Li XF. Characterization of new nitrosamines in drinking water using liquid chromatography tandem mass spectrometry. Environ Sci Technol 2006;40:7636-41.

Zhao YY, Boyd JM, Woodbeck M, Andrews RC, Qin F, Hrudey SE, et al. Formation of $\mathrm{N}$-nitrosamines from eleven disinfection treatments of seven different surface waters. Environ Sci Technol 2008;42:4857-62.

Zhou WJ, Boyd JM, Qin F, Hrudey SE, Li XF. Formation of N-nitrosodiphenylamine and two new $\mathrm{N}$-containing disinfection byproducts from chloramination of water containing diphenylamine. Environ Sci Technol 2009;43:8443-8. 